\title{
Limelight on two HIV/SIV accessory proteins in macrophage infection: Is Vpx overshadowing Vpr?
}

\author{
Diana Ayinde ${ }^{\dagger 1,2}$, Claire Maudet ${ }^{\dagger 1,2}$, Catherine Transy*1,2 and Florence Margottin-Goguet ${ }^{* 1,2}$
}

\begin{abstract}
HIV viruses encode a set of accessory proteins, which are important determinants of virulence due to their ability to manipulate the host cell physiology for the benefit of the virus. Although these viral proteins are dispensable for viral growth in many in vitro cell culture systems, they influence the efficiency of viral replication in certain cell types. Macrophages are early targets of HIV infection which play a major role in viral dissemination and persistence in the organism. This review focuses on two HIV accessory proteins whose functions might be more specifically related to macrophage infection: Vpr, which is conserved across primate lentiviruses including HIV-1 and HIV-2, and Vpx, a protein genetically related to Vpr, which is unique to HIV-2 and a subset of simian lentiviruses. Recent studies suggest that both $V p r$ and $V p x$ exploit the host ubiquitination machinery in order to inactivate specific cellular proteins. We review here why it remains difficult to decipher the role of Vpr in macrophage infection by HIV-1 and how recent data underscore the ability of $\vee p x$ to antagonize a restriction factor which counteracts synthesis of viral DNA in monocytic cells.
\end{abstract}

\section{Introduction}

The monocyte-macrophage lineage represents the only natural target common to all known lentiviruses, which include the primate immunodeficiency viruses (HIVs and SIVs). As a terminally differentiated cell, the macrophage is in a non-proliferative state. The ability to infect nondividing cells is a characteristic that is unique to members of the lentiviral genus in the retrovirus family (reviewed in [1]). It has opened a promising path in the field of gene therapy since the use of HIV-derived lentiviral vectors has dramatically expanded the range of cell types amenable to gene transfer. The consequence of this property is of course much less fortunate in the setting of natural infection since macrophages are considered major actors in HIV pathogenesis [2-4]. Macrophages are widely recognized as early targets of infection during HIV transmission. They represent long-term producers of the virus due to their higher resistance to HIV cytopathic effects and their relatively long half-life as compared to activated $\mathrm{T}$ cells [5]. Macrophages are also capable of migrating into many tissues including the brain. Altogether, these

\footnotetext{
* Correspondence: catherine.transy@inserm.fr

, florence.margottin-goguet@inserm.fr

1 Institut Cochin, Université Paris Descartes, CNRS (UMR 8104), Paris, France

1 Institut Cochin, Université Paris Descartes, CNRS (UMR 8104), Paris, France + Contributed equally

Full list of author information is available at the end of the article
}

features greatly contribute to transmission, persistence and dissemination of HIV. Accordingly, the multiple aspects of the relationship between HIV and macrophages, as well as other monocytic cells, have long been actively studied.

Sequencing of the genomes of HIV-1 and HIV-2 following their identification as causative agents of human AIDS revealed an unsuspected genetic complexity. In addition to the $g a g$, pol and env genes, which represent the prototypical retroviral genes, the HIV genomes encode two critical regulatory proteins, Tat and Rev, as well as a set of so-called accessory proteins (Figure 1). The latter were soon found to be dispensable for viral growth, at least in certain ex vivo cellular systems, hence the term "accessory". However, the emergence of these accessory proteins, which have no counterparts in other retroviral groups, strongly suggested that they fulfill specific needs of HIVs in the context of natural infection [6]. Accordingly, they have stimulated intense investigation for more than 20 years. Here we will focus on the two accessory proteins thought to be more specifically dedicated to macrophage infection by HIVs, namely Vpr, which is shared by HIV-1 and HIV-2, and Vpx, which is specific for the HIV-2/SIVsm lineage. A more general overview of HIV accessory proteins can be found in two recent reviews $[7,8]$. The unifying view that is currently emerging in this field deserves to be mentioned because it 


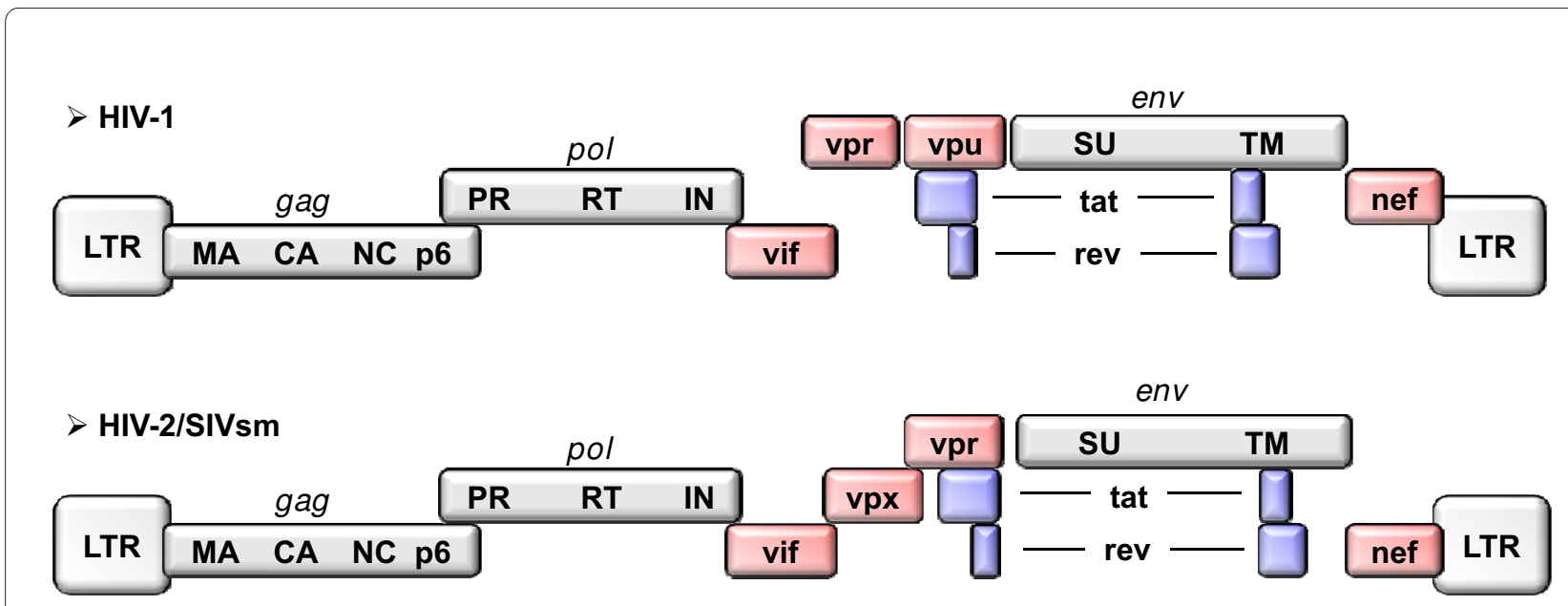

Figure 1 Schematic representation of HIV-1 and HIV-2 genomes. Grey boxes represent structural genes; blue boxes indicate regulatory genes; and pink boxes indicate accessory genes.

illustrates the quite common necessity for viruses to cope with a cellular environment that may restrict their replication in many ways. Thus, it appears that HIV accessory proteins mainly serve as a means to neutralize host factors that compromise the efficiency of viral replication in particular settings. Moreover, several of these host factors are not passive barriers but rather intrinsic antiviral cell defenses acquired during evolution.

\section{A common genetic origin for $\mathrm{Vpr}$ and $\mathrm{Vpx}$}

As mentioned above, the genome of the HIV-2 lineage encodes Vpr, an ortholog of the HIV-1 Vpr protein, and Vpx, which has no counterpart in the HIV-1 lineage [911]. Thorough comparisons soon revealed sequence similarity between $\mathrm{Vpx}$ and $\mathrm{Vpr}$, pointing to a common ancestral origin of the two genes [12-14]. This similarity extended to an important biological aspect: Vpx and Vpr were shown to be actively encapsidated through their association with the $\mathrm{p} 6$ gag product, a feature unique to these two accessory proteins [15-21]. Thus, these proteins are delivered into the cell upon virion entry, suggesting a role in the early steps of the viral life cycle which culminate in the integration of the viral cDNA into the host genome.

It is now widely accepted that HIV-1 and HIV-2 emerged from cross-species transmission of primate lentiviruses that naturally infect chimpanzees (SIVcpz) and sooty mangabeys (SIVsm) respectively [22]. Transmission events from SIVsm-infected mangabeys to macaques also occurred in captive animals giving rise to SIVmac, which causes a disease similar to human AIDS and is therefore largely used as an experimental model [23].

Besides the HIV-1 and the HIV-2/SIVsm lineages, several other lentiviral lineages have been identified in diverse African primates, prompting additional genetic comparisons and phylogenetic studies. The $\mathrm{Vpr} / \mathrm{Vpx}$ precursor gene is believed to have undergone complex duplication and recombination events during the diversification of primate lentiviruses [14].

Both SIVrcm and SIVmnd2, which infect red-capped mangabeys and mandrils respectively, carry two genes which are likely orthologs of the Vpr and Vpx genes found in the HIV-2 lineage and which have therefore been named Vpr and Vpx [24,25]. All other primate lentiviral lineages, such as African green monkey SIVagm, contain a single gene named $\mathrm{Vpr}$, in reference to the genetic organization of HIV-1 which contains only one of the two genes. However, this nomenclature might be misleading since the corresponding genes do not form a monophyletic cluster and show substantial sequence divergence from the prototypical HIV-1 Vpr [25].

\section{Role and importance of Vpr in macrophage infection by HIV viruses: absence of a clear picture}

Up until quite recently, Vpr had been presented in most publications and reviews as a protein which facilitates HIV-1 macrophage infection by contributing to nuclear import of the viral pre-integration complex (PIC) [26]. Several lines of evidence supported this view. In the retrovirus life cycle, integration of viral cDNA into the host DNA is a prerequisite for the synthesis of new virions. Unlike gammaretroviruses, lentiviruses can achieve this step independently of the nuclear envelope breakdown which occurs during mitosis, hence their ability to infect non-cycling cells. This property implies that lentiviruses such as HIVs have evolved a mechanism that enables efficient nuclear translocation of the viral PIC which is formed in the cytoplasm after completion of the reverse 
transcription step. As a virion-packaged protein, $\mathrm{Vpr}$ is present from the start of the virus life cycle and based on their finding that it also displays nucleophilic properties, $\mathrm{Lu}$ et al. hypothesized that $\mathrm{Vpr}$ might contribute to nuclear targeting of the viral PIC [27]. A number of studies provided experimental evidence consistent with this prediction although pointing to functional redundancy between $\mathrm{Vpr}$ and other karyophilic viral components such as the Matrix protein [28-34]. Moreover, it was reported that Vpr-deficient HIV-1 showed a significant replication defect in primary macrophages but not in established cell lines or activated $\mathrm{T}$ cells $[35,36]$. Thus, Vpr seemed to be required for optimal viral replication in non-cycling target cells.

However, later studies showed that HIV infection of non-cycling cells does not depend on the karyophilic properties of viral proteins [37-42]. In addition, HIV-1derived lentiviral vectors devoid of accessory proteins efficiently transduce terminally differentiated cells such as neurons [43-45]. Thus, the ability of $\mathrm{Vpr}$ to enhance infection of macrophages has to be related to specific features of these cells rather than to their non-cycling status. In further support of this hypothesis, experiments conducted using lymphoid tissue explants showed that tissue macrophages were less permissive to infection by Vprdeficient HIV-1 than by wild type HIV-1, whereas resting $\mathrm{T}$ cells within the same tissue were equally well infected by both types of viruses [46]. Therefore, it remains unclear whether a helper role in nuclear import of viral DNA represents the functional basis for Vpr-mediated increase in macrophage infection by HIV-1. It should also be noted that a role of $\mathrm{Vpr}$ in the nuclear targeting of viral DNA would rely on the Vpr pool present in the incoming virion, which was shown to be much less abundant than initially estimated [47].

It is somewhat difficult to estimate the extent of the facilitation effect of $\mathrm{Vpr}$ in macrophage infection by HIV1. In single cycle infection experiments, the absence of Vpr resulted in only a two-fold decrease in the percentage of transduced macrophages [43]. Although modest, this effect on transduction efficiency is expected to be cumulative in a spreading infection using replicative viruses. This may partly explain the much larger defect range (> 10 -fold) reported in the two studies which are commonly taken as reference $[35,36]$. Of note, in other studies, which also used propagative viruses, the lack of Vpr had a lower effect on viral replication $[28,48]$. If de novo synthesized $\mathrm{Vpr}$ contributes to the spreading of infection in macrophages, as was proposed by Connor et al [36], it might also amplify the quantitative differences between single cycle and spreading infections. In that case, the overall effect of $\mathrm{Vpr}$ would result from two distinct $\mathrm{Vpr}$ functions, the first occurring prior to viral integration and performed by the virion-delivered Vpr pool, the sec- ond taking place after viral integration and performed by de novo synthesized Vpr. Consistent with a function during the late steps of the viral life cycle, $\mathrm{Vpr}$ has been shown to stimulate HIV-1 transcription in monocytic cells [49]. Strong variations between donors were also recurrently reported regarding the effect of $\mathrm{Vpr}$ on viral replication in macrophages [35,50], adding another difficulty in interpreting the data obtained in these experimental systems. Moreover, the magnitude of Vpr's effect appears to depend on the multiplicity of infection used in the initial inoculum [51].

Although no systematic mutagenesis approach has been carried out in order to genetically dissect the helper effect of Vpr in the context of macrophage infection, several studies have addressed whether this effect segregates with another property of the protein. Remarkably, reduced viral replication in macrophages was observed for mutations of Vpr disrupting its interaction with host proteins as diverse as uracil-DNA glycosylase, hCG1 nucleoporin, importin alpha and exportin 1 [50,52-54]. Thus to date, no unifying view has emerged regarding the putative host partners of $\mathrm{Vpr}$ in its ability to increase the replicative capacity of HIV-1 in macrophages.

Finally, the functional importance of $\mathrm{Vpr}$ in macrophage infection markedly differs between lentiviral lineages. As described above, HIV-1 Vpr appears to facilitate macrophage infection but is not critical. HIV-2/ SIVsm replication was found to be only mildly - if at all affected by the lack of Vpr [55-58], whereas SIVagm was reported to be critically dependent on Vpr for macrophage infection [59]. The fact that $\mathrm{Vpr}$ knock-out shows such species-specific effects with respect to macrophage infection suggests that the Vpr genes have significantly diverged from each other in the selective advantages they confer to their cognate viruses. This also indicates, as mentioned previously, that they are not genuine orthologs.

\section{A potential link between Vpr and HIV evasion of host immune defenses}

Macrophages and dendritic cells (DC), in addition to being targets and reservoirs for HIV, play a critical role in the coordination between innate and adaptive immune responses to infection. Following detection and capture of pathogen products, these cells undergo a maturation process and deliver activation signals to antigen-specific $\mathrm{T}$ cells through both cell-cell contacts and secretion of cytokines. In turn, activated $\mathrm{T}$ cells secrete specific cytokines which potentiate both the adaptive and innate immune responses. There is increasing evidence that these complex regulatory circuits are impaired by persistent viruses such as HIVs, as a means to undermine the overall host antiviral immune response [60]. The possible contribution of $\mathrm{Vpr}$ to $\mathrm{HIV}-1$ immune escape was 
addressed by several groups. Two reports showed that Vpr downregulates the expression of Interferon regulatory factor 3 (IRF-3) [61,62], a factor which is essential for interferon (IFN) beta production in response to viral infection. The lack of IRF-3 activation during the course of HIV-1 infection is however unrelated to Vpr's effect since deletion of Vpr did not restore IFN beta production by HIV-1-infected cells [62]. A remarkably broad spectrum of Vpr-mediated immunosuppressive effects was documented in immune cells. Thus, $\mathrm{Vpr}$ was found to impair DC/macrophage maturation, to compromise natural killer (NK) effector functions, to induce apoptosis of cytotoxic $\mathrm{T}$ cells, to downregulate the production of chemokines by macrophages and T cells, and to compromise $\mathrm{T}$ cell activation pathways [63-70]. Overall, Vpr appears to impair the so-called Th1 immune response, known to be critical for antiviral immunity (reviewed in ref [71]). This raises the interesting possibility that $\mathrm{Vpr}$ contributes to viral persistence by compromising the proper cooperation between immune cells rather than by (or in addition to) modulating the viral replicative capacity at the cell level. However, there are unsolved questions and controversies. For example, several of the immunomodulatory effects of $\mathrm{Vpr}$ were observed using cells exposed to extracellular recombinant $\mathrm{Vpr}$ protein and whether this unusual way of delivering $\mathrm{Vpr}$ is biologically relevant to the setting of natural infection requires confirmation. Conflicting data have been reported regarding the effect of Vpr on NK cells. In two studies, Vpr induced anergy of bystander NK cells $[69,70]$, whereas in another study, Vpr stimulated their ability to recognize and lyse infected cells [72]. How Vpr might alter immune functions of infected or bystander cells is unclear as well. It has been proposed that $\mathrm{Vpr}$ acts by enhancing the immunosuppressive action of endogenous glucocorticoids [73] or by inhibiting the activity of NFkB, a key transcription factor in the induction of proinflammatory mediators [68]. However, opposite effects of $\mathrm{Vpr}$ on $\mathrm{NFkB}$ were reported by other investigators [49,74]. Mutations which abolish the immunosuppressive activities of Vpr have not yet been characterized. Finally, it will be important to address whether presumed orthologs of HIV-1 Vpr also show immunoregulatory properties, given that persistent infection is a hallmark of primate lentiviruses.

\section{Mechanism of Vpr-mediated cell cycle arrest: a clue for its actual function?}

Expression of $\mathrm{Vpr}$ in cycling cells triggers cell cycle arrest at the G2 phase, i.e. after completion of DNA replication and prior to mitosis. Vpr-mediated G2 arrest, which was underscored in 1995 by several groups [75-79], represents by far the most widely admitted property of the viral protein. However, the biological significance of this activity is unclear given that efficient viral replication does not require $\mathrm{Vpr}$ in dividing cells infected ex vivo. Conversely, Vpr-mediated G2 arrest is obviously irrelevant to its elusive role in HIV-1 infection of macrophages since these cells do not divide.

In spite of the above paradox, the underlying mechanism of Vpr-mediated G2 arrest has been searched for during many years. In 2007, these efforts finally bore fruit; when several studies, including ours, identified VprBP/DCAF1 as a critical host factor in the ability of Vpr to promote cell cycle arrest [80-86]. Zhao et al. had previously identified VprBP as a cellular protein binding to Vpr with high affinity [87]. Unfortunately, at the time, this finding had not drawn much attention presumably because of the plethora of proposed Vpr host partners. More recent studies in a totally different field crossed the path of VprBP, which was isolated as a member of the DDB1-Cullin4-associated factors (DCAFs) [88-91]. DDB1 represents a core component of complexes assembled by Cullin 4 (Cul4), which act as E3 ubiquitin ligases. These cellular enzymes control the selection of protein substrates that will undergo ubiquitin conjugation, a prerequisite for their subsequent proteasome-mediated degradation. In a given Cul4-based complex, substrate specificity is likely dictated by the nature of the DCAF protein bound to DBB1. Of note, while investigating another activity of Vpr, Landau's group reported the association of $\mathrm{Vpr}$ with two members of the cullin-based ubiquitin ligase family Cullin 1 and Cullin 4 [92]. Regarding the physical and functional connection between $\mathrm{Vpr}$ and VprBP, now renamed DCAF1, the data collectively obtained by the different investigators support the model depicted in Figure 2[80-85]. Vpr simultaneously recruits the Cul4A ubiquitin ligase through DCAF1 and a so far unknown cellular protein which is required for entry into mitosis. As a result, the $\mathrm{Vpr}$ target protein undergoes ubiquitination and subsequent proteasome-mediated degradation, which in turn precludes the G2/M transition of the cell cycle. Vpr itself appears to be immune to DCAF1-induced degradation and is even stabilized by its association with the Cul4A-DDB1 ubiquitin ligase [93].

Diverting the host ubiquitination machinery to inactivate an undesirable host protein is a fairly common viral strategy. Two HIV-1 accessory proteins have previously been shown to use this mechanism. Vpu promotes destabilization of the intracellular pool of CD4 [94], to ensure the liberation of infectious viruses, and inactivates BST2/tetherin, a cellular membrane protein which traps newly synthesized virions at the cell surface [95-97]. Vif induces the degradation of the antiviral APOBEC3G and APOBEC3F enzymes, preventing their incorporation into newly formed virions and therefore avoiding their deleterious effects during the following infection cycle [98101]. 


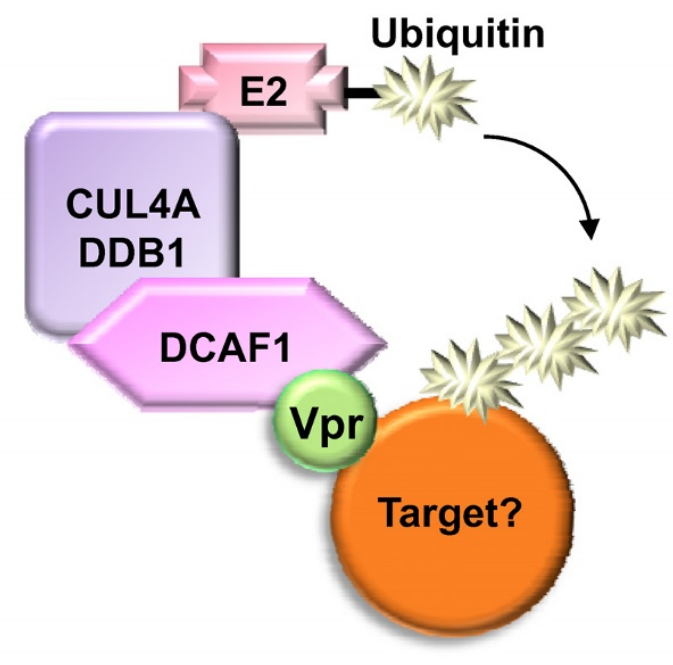

Figure 2 Model for HIV-1 Vpr mechanism of action. HIV-1 Vpr recruits the Cul4A-DDB1 ubiquitin ligase through DCAF1 binding, which leads to the ubiquitination and inactivation of an unknown cellular target required for entry into mitosis.

It should be stressed that the model proposed for the Vpr mechanism of action does not enlighten us about the biological significance of G2 arrest in the context of viral infection. As already mentioned, $\mathrm{Vpr}$ does not confer a measurable growth advantage to HIV in the dividing cells used for ex vivo infection experiments. However, both the transcription and the translation of viral genes reach maximal levels during the G2/M phase of cell cycle and it has been suggested that in the context of natural infection, Vpr-mediated G2 arrest could serve as a means to optimize viral production by the short-lived infected cells $[102,103]$. In view of our present knowledge of Vpr's mechanism of action, one might also consider that the intended effect of Vpr is the degradation of a specific host protein rather than the resulting cell cycle arrest. In this case, the Vpr host target is expected to be detrimental for viral replication or persistence in the context of natural infection in vivo. Identification of the host protein(s) targeted for degradation by $\mathrm{Vpr}$ will certainly be instrumental for our understanding of the genuine function of this accessory protein.

Vpr from the SIVsm/HIV-2 lineage also binds DCAF1 $[82,86]$ and triggers $G 2$ arrest albeit less efficiently than HIV-1 Vpr [56,86,104-107]. This strongly suggests that the $\mathrm{Vpr}$ proteins from HIV-1 and HIV-2 use the same mechanism of action and target at least one common host protein. The latter is, however, unlikely to play a role in the relationship between HIVs and macrophages given that Vpr-deficient HIV-2 efficiently replicate in these cells. That an additional factor is inactivated by HIV-1 Vpr to facilitate macrophage infection might, however, be envisioned in light of the recently revealed ability of $\mathrm{Vpr}$ to divert the host ubiquitination machinery.

\section{An earlier view of $\mathrm{Vpx}$ as the functional counterpart of HIV- $1 \mathrm{Vpr}$ in macrophage infection}

As previously mentioned, members of the HIV-2/SIVsm lineage carry both $\mathrm{Vpr}$ and $\mathrm{Vpx}$, the latter being specific to this lineage (Figure 1). The common genetic origin of Vpr and Vpx raised the question of their respective functions in the HIV-2 lineage as compared to that of the single Vpr protein encoded by HIV-1.

Early data showed that Vpr from HIV-2/SIVsm, like Vpr from HIV-1, had the ability to arrest the cell cycle at the G2 phase whereas Vpx had no effect on cell cycle progression [56,104-106]. However, several lines of evidence supported a role for $\mathrm{Vpx}$ in the nuclear import of viral DNA in non-dividing cells. First, a number of studies reported that Vpx is critical for the infection of nondividing macrophages, but not of cycling cells $[56,108,109]$. Secondly, the replication defect induced by Vpx mutants correlated with the failure to promote accumulation of 2LTR circles, which are considered as markers of viral DNA entry into the nucleus. Finally, the nuclear localization of $\mathrm{Vpx}$ in macrophages was consistent with its ability to promote productive infection [110113]. Therefore, it was hypothesized that the two activities attributed to HIV-1 Vpr had somehow segregated in the HIV-2/SIVsm lineage: the ability to induce G2 arrest became specific to $\mathrm{Vpr}$ in this lineage, and the ability to import viral DNA into the nucleus became specific to Vpx [56]. However, uncertainties remained regarding the role of Vpx in viral DNA nuclear import. Some studies reported a role of $\mathrm{Vpx}$ in the infection of dividing $\mathrm{T}$ cells in addition to its role in macrophages [57,58,114-118], while other studies failed to detect a nuclear localization of Vpx [119]. Of note, Vpx was also found to interfere with the reverse transcription step in early studies. However, this effect appeared minor compared to the effect on the viral DNA nuclear import and therefore was not further investigated [56].

\section{First evidence that $\mathrm{Vpx}$ is not the functional counterpart of HIV-1 Vpr in macrophage infection}

Although the deletion of $\mathrm{Vpr}$ in $\mathrm{HIV}-1$ induces a moderate decrease of HIV-1 transduction in macrophages, its effect was minor compared to that of Vpx in SIV/HIV-2 $[58,112,115,118,120]$. The requirement for $\mathrm{Vpx}$ is even stronger in monocytes and in monocyte-derived dendritic cells infected by SIVmac, in which cell transduction is entirely dependent on its presence [121-124]. These data underscore the major role of Vpx during the infection of cells from the monocytic lineage. As already mentioned, the picture is not very clear in lymphoid cells 
where the dependence on Vpx for viral growth is still controversial.

In vivo experiments in macaque models also pointed out major differences between viruses deleted for Vpr or Vpx [125,126]. Surprisingly, in the two studies, Vprdeleted viruses behaved similarly to the wt viruses. In experiments using the acutely pathogenic virus $\mathrm{SIVsmPBj}$ inoculated into pigtailed macaques, the effect of $\mathrm{Vpx}$ deletion is dramatic: macaques infected with the wt virus developed fulminant disease whereas animals inoculated with the Vpx-deleted virus showed delayed kinetics of viral replication and no disease manifestations [126]. In the study using rhesus monkeys infected with a virus derived from SIVmac239, progression to death occurred in the absence of a gene for Vpx, but lower virus burdens and delayed disease induction were noticed [125].

The essential role of Vpx both in cells from the monocytic lineage and in vivo suggests that $\mathrm{Vpx}$ is not just a pale imitation of $\mathrm{Vpr}$ in its ability to transport the viral DNA.

\section{A specific function for Vpx: degradation of a cellular restriction factor in macrophages}

It came as a surprise when Vpx was found to promote the accumulation of HIV-2/SIV reverse transcripts and therefore to act prior to the transport of the pre-integration complex. These findings were first demonstrated in monocyte-derived dendritic cells and thereafter in macrophages [55,122,127-129]. Whether Vpx plays a role in nuclear import of viral DNA in addition to its role at the reverse transcription step remains a subject of debate [109].

It appeared unlikely that Vpx targeted HIV and SIV viral components since the effect of Vpx, which is particularly dramatic in dendritic cells, appeared to be cell-type dependent and since Vpx facilitated viral transduction of dendritic cells with retroviruses as divergent as primate lentiviruses (HIV-1), non-primate lentiviruses (FIV) or gammaretroviruses (murine leukemia viruses) [122]. The question was, did Vpx complement the lack of a cellular activity, such as viral DNA nuclear import, or did Vpx counteract an antiviral activity present in dendritic cells. The ability of the proteasome inhibitor MG132 to partially restore infectivity of Vpx-deficient SIVmac lentiviral particles led Cimarelli's group to propose that Vpx promotes retroviral escape from a proteasome-dependent restriction pathway present in monocyte-derived dendritic cells [122]. Based on sequence homology between Vpr and Vpx, we predicted that Vpx may divert the same ubiquitin ligase as Vpr and we demonstrated, using a two hybrid system that Vpx from SIVsmPBj physically interacts with the DCAF1 adaptor subunit of the Cul4ADDB1 ubiquitin ligase [83]. Binding of Vpx from SIV or HIV-2 to DCAF1 was further confirmed in mammalian cells $[55,129,130]$. Altogether, the data pointed to a hypothesis in which Vpx would use the DCAF1 ubiquitin ligase to get rid of a cellular restriction factor present in dendritic cells and in macrophages. This hypothesis received experimental support in macrophages in the context of SIVsmPBj, SIVmac239 and HIV-2 infection $[55,129,130]$. Stevenson's group demonstrated that Vpx counteracts a macrophage-specific restriction factor using heterokaryons, a technique previously adopted to characterize the mechanism of action of another HIV accessory protein, Vif $[131,132]$. Heterokaryons generated between COS cells, in which Vpx is dispensable for virus infection, and macrophages, in which Vpx is essential for virus infection, supported transduction by wt SIV but not Vpx-deleted SIV [130]. This definitively discarded the possibility that Vpx may complement the lack of a cellular factor necessary for viral replication in macrophages. Vpx, like Vpr, is a virion-incorporated protein and was therefore expected to perform its function prior to de novo synthesis of viral proteins in the target cell. In agreement with this, infection of macrophages harboring wt Vpx alleviated the block to subsequent infection by Vpx-deficient SIV, providing evidence that Vpx delivered in trans can counteract the restriction [130]. Two studies showed that inactivation of the DCAF1-binding property of Vpx mimicked the absence of Vpx, impairing HIV-2/ SIV growth in macrophages. In addition, silencing of DCAF1 or DDB1 impaired replication of wt HIV-2/SIV $[55,129,130]$. This latter result argues against a model in which Vpx would inhibit the endogenous activity of the ubiquitin ligase, and subsequently prevent the degradation of a positive factor, but rather favors a model in which Vpx diverts the activity of the Cul4A-DDB1 ${ }^{\text {DCAF1 }}$ complex to induce the degradation of a macrophage-specific restriction factor (Figure 3 ).

What properties can be attributed to this restriction factor? We must underline here that the restriction factor targeted by Vpx is unlikely to also be inactivated by HIV-1 Vpr since infectivity of Vpr-deleted HIV-1 is dramatically enhanced in macrophages by Vpx but not by HIV-1 Vpr $[7,121,130]$.

The restriction factor antagonized by Vpx appears to inhibit the accumulation of reverse transcripts, a step which is also targeted by the Trim $5 \alpha$ restriction factor [133-137]. However, the two proteins differ in many aspects. In contrast to $\operatorname{Trim} 5 \alpha$, the restriction factor antagonized by Vpx should be conserved across primate species since SIVsm Vpx can substitute HIV-2 Vpx in HIV-2 macrophage infection and HIV-2 Vpx can complement Vpx-defective SIVmac. Also in contrast to Trim5 $\alpha$, which is ubiquitous, the Vpx-targeted restriction factor is specific of the monocytic lineage. However, unlike $\operatorname{Trim} 5 \alpha$, this restriction factor is probably not saturable, at least in dendritic cells, since high amounts of viral par- 


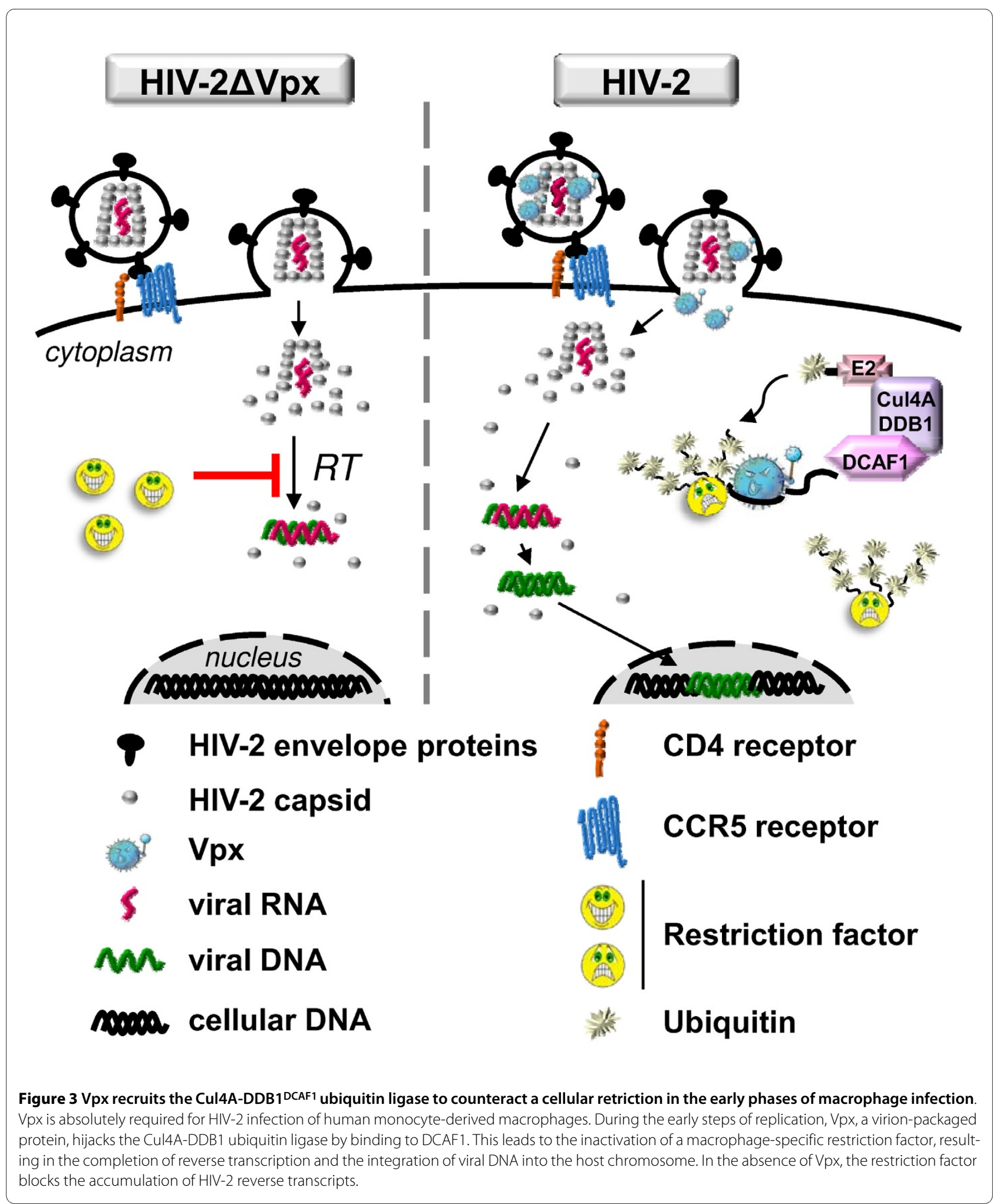

ticles fail to restore infectivity of Vpx-deficient SIVmac $[122,123]$. Similarly to Trim $5 \alpha$ though, the Vpx-antagonized factor is type I IFN-inducible as highlighted lately by a report [7].
Recently, Vpx has been shown to counteract a cellular restriction in monocytes, which are highly susceptible to SIVsmPBj infection provided that Vpx is expressed $[124,128,138]$. Whether a unique restriction factor is 
antagonized by Vpx in macrophages, dendritic cells and monocytes remains to be clarified. In the latter, the potential dependence on the Cul4A-DDB1 ${ }^{\text {DCAF1 }}$ ubiquitin ligase has not been addressed. Surprisingly, a DCAF1independent role of $\mathrm{Vpx}$ has been described in dendritic cells, as well as in differentiated monocytic THP1 cells which are supposed to recapitulate the functional properties of macrophages [121]. The possibility remains that Vpx uses different mechanisms in different cell types to counteract a cellular restriction. It is striking however, that Vpx in both macrophages and dendritic cells acts at the level of reverse transcription. Further investigations will be needed to understand whether the reverse transcription step itself is inhibited by the cellular restriction, whether an abnormal destruction of the newly synthesized viral cDNA occurs, or whether a step prior to the reverse transcription is affected.

The ability of HIV-1 to transduce macrophages, and to a lesser extent dendritic cells, in the absence of any accessory proteins may suggest that the cellular restriction factor antagonized by $\mathrm{Vpx}$ senses a viral component that is highly specific for HIV-2/SIVsm and which is not present in HIV-1. However, the restriction antagonized by Vpx is also active against HIV-1 since Vpx increases the permissivity of dendritic cells and macrophages to HIV-1. In addition, monocytes, which are normally refractory to HIV-1, become permissive in the presence of $\mathrm{Vpx}$ $[121,122,128,130,138-140]$. In macrophages, the helper effect of Vpx towards HIV-1 transduction has been shown to depend on DDB1 [130] and thus probably also relies on the hijacking of the Cul4A ubiquitin ligase, leading to subsequent degradation of an inhibitory factor. Whether such a mechanism exists in monocytes has not been addressed yet. If the same restriction factor antagonizes HIV-1 in monocytes and macrophages, its level of expression is expected to be higher in monocytes due to their resistance to $\mathrm{HIV}-1$ infection (c.f. the accompanying review by A. Bergamaschi and G. Pancino).

\section{Vpr and Vpx: rival brothers?}

To date, the only functional characteristic common to Vpr and Vpx is their ability to recruit the Cul4A ubiquitin ligase. This raises the possibility that Vpr and Vpx compete for function. In the early steps of the viral life cycle, such a competition is difficult to envision given that the amount of virion-bound $\mathrm{Vpr}$ and $\mathrm{Vpx}$ is minor compared to the pool of DCAF1. In addition, it has been shown that deletion of $\mathrm{Vpr}$ does not affect Vpx-dependent HIV-2/ SIV infection $[7,55]$. However, in later steps of viral infection, competition might occur assuming that the amount of de novo synthesized $\mathrm{Vpr}$ and $\mathrm{Vpx}$ now exceed that of DCAF1. Consistent with this possibility, G2 arrest-defective mutants of $\mathrm{Vpr}$ which conserve DCAF1-binding activity were shown to inhibit G2 arrest induced by wt
Vpr, suggesting that the amount of DCAF1 might be limiting $[81,83]$. Whether this probable competition in turn affects $\mathrm{Vpr}$ and Vpx functions requires further investigation.

\section{Conclusion}

The ability to recruit the Cul4A ubiquitin ligase is shared by Vpr and Vpx proteins from diverse lentiviral origins, suggesting that this trait was acquired early in the evolution of the vpr-like gene family. While conserving this functional characteristic, $\mathrm{Vpr}$ and $\mathrm{Vpx}$ have likely diverged in the nature of the substrates they target and therefore in their respective functions. The modest effect of HIV-1 Vpr deletion on viral replication in macrophages and the absence of a clear phenotype in ex vivo cell cultures for Vpr-deleted HIV-1 raised questions regarding the true role of $\mathrm{Vpr}$ in viral infection. Further investigation is required to understand whether Vpr plays a role in early steps of infection, as expected considering its virion-bound nature, or whether $\mathrm{Vpr}$ plays a more indirect role by regulating the spread and (or) persistence of infection, as would suggest its reported immunomodulatory properties $[65,66,69,70]$. What is certain is that $\mathrm{Vpr}$ must confer some selective advantage to the virus since reversion events in vpr occur rapidly in rhesus monkeys infected with Vpr-defective SIVmac [125]. The requirement for the Cul4A-DDB1 ${ }^{\text {DCAF1 }}$ ubiquitin ligase, which was first shown for $\mathrm{Vpr}$, has not unravelled the role of Vpr-mediated G2 arrest during viral infection. Somewhat ironically, this property has enlightened the underlying mechanism of the well known critical function of Vpx in macrophage infection. It is now widely acknowledged that Vpx specifically counteracts a cellular restriction present in macrophages leading to establishment and productive spread of infection. Why HIV-1 Vpr has not kept or acquired this powerful activity from an ancestral vpr-like gene remains a mystery, in particular since this restriction appears to be active against HIV-1 [122,130]. The discovery of the cellular target(s) of Vpr and Vpx will provide great help in understanding the susceptibility of cells from the monocytic lineage to infection by both HIV-1 and HIV-2/SIVsm. This might in turn lead to the elaboration of antiviral strategies to prevent viruses from establishing reservoirs in these cells.

\section{Competing interests}

The authors declare that they have no competing interests.

\section{Authors' contributions}

CT and FMG conceived and wrote the review. DA and CM conceived the illustrations and were involved in discussions and critical reading of the manuscript.

\section{Acknowledgements}

The authors fully apologize to all those they may have omitted to reference. This work was supported by grants from the "Agence Nationale de la Recherche sur le SIDA et les hépatites virales" (ANRS), "Sidaction" and "Fondation de 
France". This review is issued from a reflection conducted by the Association for Macrophage and Infection Research (AMIR). Article processing charges are paid by the Concerted Action 31 (Dendritic cells, Antigen Presentation and Innate Immunity » of ANRS. CM and DA receive support from the University Paris Diderot and the "Ministère de l'Enseignement Supérieur et de la Recherche".

\section{Author Details}

1'Institut Cochin, Université Paris Descartes, CNRS (UMR 8104), Paris, France and 2Inserm, U567, 27 rue du faubourg St Jacques 75014 Paris, France

Received: 30 September 2009 Accepted: 9 April 2010

Published: 9 April 2010

\section{References}

1. Yamashita M, Emerman M: Retroviral infection of non-dividing cells: old and new perspectives. Virology 2006, 344:88-93.

2. Coleman CM, Wu L: HIV interactions with monocytes and dendritic cells: viral latency and reservoirs. Retrovirology 2009, 6:51.

3. Carter CA, Ehrlich LS: Cell biology of HIV-1 infection of macrophages. Annu Rev Microbio/ 2008, 62:425-443.

4. Verani A, Gras G, Pancino G: Macrophages and HIV-1: dangerous liaisons. Mol Immunol 2005, 42:195-212.

5. Alexaki A, Liu Y, Wigdahl B: Cellular reservoirs of HIV-1 and their role in viral persistence. Curr HIV Res 2008, 6:388-400.

6. Trono D: When accessories turn out to be essential. Nat Med 1998, 4:1368-1369.

7. Gramberg T, Sunseri N, Landau NR: Accessories to the crime: recent advances in HIV accessory protein biology. Curr HIV/AIDS Rep 2009, 6:36-42.

8. Malim MH, Emerman M: HIV-1 accessory proteins--ensuring viral survival in a hostile environment. Cell Host Microbe 2008, 3:388-398.

9. Cohen EA, Terwilliger EF, Jalinoos Y, Proulx J, Sodroski JG, Haseltine WA: Identification of HIV-1 vpr product and function. J Acquir Immune Defic Syndr 1990, 3:11-18.

10. Henderson LE, Sowder RC, Copeland TD, Benveniste RE, Oroszlan S: Isolation and characterization of a novel protein (X-ORF product) from SIV and HIV-2. Science 1988, 241:199-201.

11. Kappes JC, Morrow CD, Lee SW, Jameson BA, Kent SB, Hood LE, Shaw GM, $\mathrm{Hahn} \mathrm{BH}$ : Identification of a novel retroviral gene unique to human immunodeficiency virus type 2 and simian immunodeficiency virus SIVMAC. J Virol 1988, 62:3501-3505.

12. Sharp PM, Bailes E, Stevenson M, Emerman M, Hahn BH: Gene acquisition in HIV and SIV. Nature 1996, 383:586-587.

13. Tristem M, Marshall C, Karpas A, Hill F: Evolution of the primate lentiviruses: evidence from vpx and vpr. Embo J 1992, 11:3405-3412.

14. Tristem M, Purvis A, Quicke DL: Complex evolutionary history of primate lentiviral vpr genes. Virology 1998, 240:232-237.

15. Kewalramani VN, Emerman M: Vpx association with mature core structures of HIV-2. Virology 1996, 218:159-168.

16. Wu X, Conway JA, Kim J, Kappes JC: Localization of the Vpx packaging signal within the $C$ terminus of the human immunodeficiency virus type 2 Gag precursor protein. J Virol 1994, 68:6161-6169.

17. Accola MA, Bukovsky AA, Jones MS, Gottlinger HG: A conserved dileucine-containing motif in p6(gag) governs the particle association of Vpx and Vpr of simian immunodeficiency viruses SIV(mac) and SIV(agm). J Virol 1999, 73:9992-9999.

18. Bachand F, Yao XJ, Hrimech M, Rougeau N, Cohen EA: Incorporation of $V p r$ into human immunodeficiency virus type 1 requires a direct interaction with the p6 domain of the p55 gag precursor. J Biol Chem 1999, 274:9083-9091.

19. Cohen EA, Dehni G, Sodroski JG, Haseltine WA: Human immunodeficiency virus vpr product is a virion-associated regulatory protein. J Virol 1990, 64:3097-3099.

20. Kondo $\mathrm{E}$, Gottlinger HG: A conserved LXXLF sequence is the major determinant in p6gag required for the incorporation of human immunodeficiency virus type 1 Vpr. J Virol 1996, 70:159-164.

21. Paxton W, Connor Rl, Landau NR: Incorporation of Vpr into human immunodeficiency virus type 1 virions: requirement for the p6 region of gag and mutational analysis. J Virol 1993, 67:7229-7237.
22. Sharp PM, Bailes E, Chaudhuri RR, Rodenburg CM, Santiago MO, Hahn BH: The origins of acquired immune deficiency syndrome viruses: where and when? Philos Trans R Soc Lond B Biol Sci 2001, 356:867-876.

23. Hirsch VM, Dapolito G, Goeken R, Campbell BJ: Phylogeny and natural history of the primate lentiviruses, SIV and HIV. Curr Opin Genet Dev 1995, 5:798-806.

24. Beer BE, Foley BT, Kuiken CL, Tooze Z, Goeken RM, Brown CR, Hu J, St Claire $M$, Korber BT, Hirsch VM: Characterization of novel simian immunodeficiency viruses from red-capped mangabeys from Nigeria (SIVrcmNG409 and -NG411). J Virol 2001, 75:12014-12027.

25. Hu J, Switzer WM, Foley BT, Robertson DL, Goeken RM, Korber BT, Hirsch VM, Beer BE: Characterization and comparison of recombinant simian immunodeficiency virus from drill (Mandrillus leucophaeus) and mandrill (Mandrillus sphinx) isolates. J Virol 2003, 77:4867-4880.

26. Fassati A: HIV infection of non-dividing cells: a divisive problem. Retrovirology 2006, 3:74.

27. Lu YL, Spearman $P$, Ratner L: Human immunodeficiency virus type 1 viral protein $\mathrm{R}$ localization in infected cells and virions. J Virol 1993, 67:6542-6550

28. Heinzinger NK, Bukinsky MI, Haggerty SA, Ragland AM, Kewalramani V, Lee MA, Gendelman HE, Ratner L, Stevenson M, Emerman M: The Vpr protein of human immunodeficiency virus type 1 influences nuclear localization of viral nucleic acids in nondividing host cells. Proc Natl Acad Sci USA 1994, 91:7311-7315.

29. Bukrinsky MI, Haggerty S, Dempsey MP, Sharova N, Adzhubel A, Spitz L, Lewis P, Goldfarb D, Emerman M, Stevenson M: A nuclear localization signal within HIV-1 matrix protein that governs infection of nondividing cells. Nature 1993, 365:666-669.

30. Gallay P, Swingler S, Song J, Bushman F, Trono D: HIV nuclear import is governed by the phosphotyrosine-mediated binding of matrix to the core domain of integrase. Cell 1995, 83:569-576.

31. Gallay P, Swingler S, Aiken C, Trono D: HIV-1 infection of nondividing cells: C-terminal tyrosine phosphorylation of the viral matrix protein is a key regulator. Cell 1995, 80:379-388.

32. von Schwedler U, Kornbluth RS, Trono D: The nuclear localization signa of the matrix protein of human immunodeficiency virus type 1 allows the establishment of infection in macrophages and quiescent $T$ lymphocytes. Proc Natl Acad Sci USA 1994, 91:6992-6996.

33. Popov S, Rexach M, Zybarth G, Reiling N, Lee MA, Ratner L, Lane CM, Moore MS, Blobel G, Bukrinsky M: Viral protein R regulates nuclear import of the HIV-1 pre-integration complex. Embo J 1998, 17:909-917.

34. Vodicka MA, Koepp DM, Silver PA, Emerman M: HIV-1 Vpr interacts with the nuclear transport pathway to promote macrophage infection. Genes Dev 1998, 12:175-185.

35. Balliet JW, Kolson DL, Eiger G, Kim FM, McGann KA, Srinivasan A, Collman $R$ : Distinct effects in primary macrophages and lymphocytes of the human immunodeficiency virus type 1 accessory genes vpr, vpu, and nef: mutational analysis of a primary HIV-1 isolate. Virology 1994, 200:623-631.

36. Connor RI, Chen BK, Choe S, Landau NR: Vpr is required for efficient replication of human immunodeficiency virus type-1 in mononuclear phagocytes. Virology 1995, 206:935-944

37. Dvorin JD, Bell P, Maul GG, Yamashita M, Emerman M, Malim MH: Reassessment of the roles of integrase and the central DNA flap in human immunodeficiency virus type 1 nuclear import. J Virol 2002, 76:12087-12096.

38. Fouchier RA, Meyer BE, Simon JH, Fischer U, Malim MH: HIV-1 infection of non-dividing cells: evidence that the amino-terminal basic region of the viral matrix protein is important for Gag processing but not for post-entry nuclear import. Embo J 1997, 16:4531-4539.

39. Freed EO, Englund G, Maldarelli F, Martin MA: Phosphorylation of residue 131 of HIV-1 matrix is not required for macrophage infection. Cell 1997, 88:171-173. discussion 173-174

40. Limon A, Nakajima N, Lu R, Ghory HZ, Engelman A: Wild-type levels of nuclear localization and human immunodeficiency virus type 1 replication in the absence of the central DNA flap. J Virol 2002, 76:12078-12086.

41. Petit C, Schwartz O, Mammano F: The karyophilic properties of human immunodeficiency virus type 1 integrase are not required for nuclear import of proviral DNA. J Virol 2000, 74:7119-7126. 
42. Yamashita M, Emerman M: The cell cycle independence of HIV infections is not determined by known karyophilic viral elements. PLOS Pathog 2005, 1:e18.

43. Zufferey R, Nagy D, Mandel RJ, Naldini L, Trono D: Multiply attenuated lentiviral vector achieves efficient gene delivery in vivo. Nat Biotechnol 1997, 15:871-875.

44. Baekelandt V, Claeys A, Eggermont K, Lauwers E, De Strooper B, Nuttin B, Debyser Z: Characterization of lentiviral vector-mediated gene transfer in adult mouse brain. Hum Gene Ther 2002, 13:841-853.

45. Zennou V, Serguera C, Sarkis C, Colin P, Perret E, Mallet J, Charneau P: The HIV-1 DNA flap stimulates HIV vector-mediated cell transduction in the brain. Nat Biotechnol 2001, 19:446-450.

46. Eckstein DA, Sherman MP, Penn ML, Chin PS, De Noronha CM, Greene WC, Goldsmith MA: HIV-1 Vpr enhances viral burden by facilitating infection of tissue macrophages but not nondividing CD4+ T cells. J Exp Med 2001, 194:1407-1419.

47. Muller B, Tessmer U, Schubert U, Krausslich HG: Human immunodeficiency virus type $1 \mathrm{Vpr}$ protein is incorporated into the virion in significantly smaller amounts than gag and is phosphorylated in infected cells. J Virol 2000, 74:9727-9731.

48. Kawamura M, Ishizaki T, Ishimoto A, Shioda T, Kitamura T, Adachi A: Growth ability of human immunodeficiency virus type 1 auxiliary gene mutants in primary blood macrophage cultures. J Gen Virol 1994, 75(Pt 9):2427-2431.

49. Varin A, Decrion AZ, Sabbah E, Quivy V, Sire J, Van Lint C, Roques BP, Aggarwal BB, Herbein G: Synthetic Vpr protein activates activator protein-1, c-Jun N-terminal kinase, and NF-kappaB and stimulates HIV1 transcription in promonocytic cells and primary macrophages. J Biol Chem 2005, 280:42557-42567.

50. Jacquot G, Le Rouzic E, David A, Mazzolini J, Bouchet J, Bouaziz S, Niedergang F, Pancino G, Benichou S: Localization of HIV-1 Vpr to the nuclear envelope: impact on Vpr functions and virus replication in macrophages. Retrovirology 2007, 4:84.

51. Gallay P, Hope T, Chin D, Trono D: HIV-1 infection of nondividing cells through the recognition of integrase by the importin/karyopherin pathway. Proc Natl Acad Sci USA 1997, 94:9825-9830.

52. Chen R, Le Rouzic E, Kearney JA, Mansky LM, Benichou S: Vpr-mediated incorporation of UNG2 into HIV-1 particles is required to modulate the virus mutation rate and for replication in macrophages. $\mathrm{J}$ Bio/ Chem 2004, 279:28419-28425.

53. Nitahara-Kasahara $Y$, Kamata M, Yamamoto $T$, Zhang $X$, Miyamoto $Y$, Muneta K, lijima S, Yoneda Y, Tsunetsugu-Yokota Y, Aida Y: Novel nuclear import of Vpr promoted by importin alpha is crucial for human immunodeficiency virus type 1 replication in macrophages. J Virol 2007, 81:5284-5293.

54. Sherman MP, de Noronha CM, Eckstein LA, Hataye J, Mundt P, Williams SA, Neidleman JA, Goldsmith MA, Greene WC: Nuclear export of Vpr is required for efficient replication of human immunodeficiency virus type 1 in tissue macrophages. J Virol 2003, 77:7582-7589.

55. Bergamaschi A, Ayinde D, David A, Le Rouzic E, Morel M, Collin G, Descamps D, Damond F, Brun-Vezinet F, Nisole S, Margottin-Goguet F Pancino G, Transy C: The human immunodeficiency virus type $2 \mathrm{Vpx}$ protein usurps the CUL4A-DDB1 DCAF1 ubiquitin ligase to overcome a postentry block in macrophage infection. J Virol 2009, 83:4854-4860.

56. Fletcher TM, Brichacek B, Sharova N, Newman MA, Stivahtis G, Sharp PM, Emerman M, Hahn BH, Stevenson M: Nuclear import and cell cycle arrest functions of the HIV-1 Vpr protein are encoded by two separate genes in HIV-2/SIV(SM). Embo J 1996, 15:6155-6165.

57. Park IW, Sodroski J: Functional analysis of the vpx, vpr, and nef genes of simian immunodeficiency virus. J Acquir Immune Defic Syndr Hum Retrovirol 1995, 8:335-344.

58. Ueno F, Shiota H, Miyaura M, Yoshida A, Sakurai A, Tatsuki J, Koyama AH, Akari H, Adachi A, Fujita M: Vpx and Vpr proteins of HIV-2 up-regulate the viral infectivity by a distinct mechanism in lymphocytic cells. Microbes Infect 2003, 5:387-395.

59. Campbell BJ, Hirsch VM: Vpr of simian immunodeficiency virus of African green monkeys is required for replication in macaque macrophages and lymphocytes. J Virol 1997, 71:5593-5602.

60. Liu B, Woltman AM, Janssen HL, Boonstra A: Modulation of dendritic cell function by persistent viruses. J Leukoc Biol 2009, 85:205-214.

61. Doehle BP, Hladik F, McNevin JP, McElrath MJ, Gale M Jr: Human immunodeficiency virus type 1 mediates global disruption of innate antiviral signaling and immune defenses within infected cells. J Virol 2009, 83:10395-10405

62. Okumura A, Alce T, Lubyova B, Ezelle H, Strebel K, Pitha PM: HIV-1 accessory proteins VPR and Vif modulate antiviral response by targeting IRF-3 for degradation. Virology 2008, 373:85-97.

63. Muthumani K, Kudchodkar S, Papasavvas E, Montaner LJ, Weiner DB, Ayyavoo V: HIV-1 Vpr regulates expression of beta chemokines in human primary lymphocytes and macrophages. J Leukoc Biol 2000, 68:366-372.

64. Ayyavoo V, Muthumani K, Kudchodkar S, Zhang D, Ramanathan P, Dayes NS, Kim JJ, Sin Jl, Montaner LJ, Weiner DB: HIV-1 viral protein R compromises cellular immune function in vivo. Int Immunol 2002, $14: 13-22$

65. Muthumani K, Hwang DS, Choo AY, Mayilvahanan S, Dayes NS, Thieu KP, Weiner DB: HIV-1 Vpr inhibits the maturation and activation of macrophages and dendritic cells in vitro. Int Immunol 2005, 17:103-116.

66. Majumder B, Janket ML, Schafer EA, Schaubert K, Huang XL, Kan-Mitchell J, Rinaldo CR Jr, Ayyavoo V: Human immunodeficiency virus type $1 \mathrm{Vpr}$ impairs dendritic cell maturation and T-cell activation: implications for viral immune escape. J Virol 2005, 79:7990-8003.

67. Majumder B, Venkatachari NJ, Schafer EA, Janket ML, Ayyavoo V: Dendritic cells infected with vpr-positive human immunodeficiency virus type 1 induce CD8+ T-cell apoptosis via upregulation of tumor necrosis factor alpha. J Virol 2007, 81:7388-7399.

68. Venkatachari NJ, Majumder B, Ayyavoo V: Human immunodeficiency virus (HIV) type $1 \mathrm{Vpr}$ induces differential regulation of T cell costimulatory molecules: direct effect of Vpr on T cell activation and immune function. Virology 2007, 358:347-356.

69. Majumder B, Venkatachari NJ, O'Leary S, Ayyavoo V: Infection with Vprpositive human immunodeficiency virus type 1 impairs NK cell function indirectly through cytokine dysregulation of infected target cells. J Virol 2008, 82:7189-7200

70. Hong HS, Bhatnagar N, Ballmaier M, Schubert U, Henklein P, Volgmann T, Heiken H, Schmidt RE, Meyer-Olson D: Exogenous HIV-1 Vpr disrupts IFN-alpha response by plasmacytoid dendritic cells ( $p D C s$ ) and subsequent pDC/NK interplay. Immunol Lett 2009, 125:100-104.

71. Majumder B, Venkatachari NJ, Srinivasan A, Ayyavoo V: HIV-1 mediated immune pathogenesis: spotlight on the role of viral protein $\mathrm{R}(\mathrm{Vpr})$. Curr HIV Res 2009, 7:169-177.

72. Ward J, Davis Z, DeHart J, Zimmerman E, Bosque A, Brunetta E, Mavilio D Planelles V, Barker E: HIV-1 Vpr triggers natural killer cell-mediated lysis of infected cells through activation of the ATR-mediated DNA damage response. PLOS Pathog 2009, 5:e1000613.

73. Mirani M, Elenkov I, Volpi S, Hiroi N, Chrousos GP, Kino T: HIV-1 protein Vpr suppresses IL-12 production from human monocytes by enhancing glucocorticoid action: potential implications of Vpr coactivator activity for the innate and cellular immunity deficits observed in HIV-1 infection. J Immunol 2002, 169:6361-6368.

74. Roux P, Alfieri C, Hrimech M, Cohen EA, Tanner JE: Activation of transcription factors NF-kappaB and NF-IL- 6 by human immunodeficiency virus type 1 protein $\mathrm{R}(\mathrm{Vpr})$ induces interleukin-8 expression. J Virol 2000, 74:4658-4665

75. He J, Choe S, Walker R, Di Marzio P, Morgan DO, Landau NR: Human immunodeficiency virus type 1 viral protein $R(V p r)$ arrests cells in the G2 phase of the cell cycle by inhibiting p34cdc2 activity. J Virol 1995, 69:6705-6711.

76. Jowett JB, Planelles V, Poon B, Shah NP, Chen ML, Chen IS: The human immunodeficiency virus type $1 \mathrm{vpr}$ gene arrests infected T cells in the G2 + M phase of the cell cycle. J Virol 1995, 69:6304-6313.

77. Planelles V, Bachelerie F, Jowett JB, Haislip A, Xie Y, Banooni P, Masuda T, Chen IS: Fate of the human immunodeficiency virus type 1 provirus in infected cells: a role for vpr. J Virol 1995, 69:5883-5889.

78. Re F, Braaten D, Franke EK, Luban J: Human immunodeficiency virus type $1 \mathrm{Vpr}$ arrests the cell cycle in $\mathrm{G} 2$ by inhibiting the activation of p34cdc2-cyclin B. J Virol 1995, 69:6859-6864.

79. Rogel ME, Wu LI, Emerman M: The human immunodeficiency virus type 1 vpr gene prevents cell proliferation during chronic infection. J Virol 1995, 69:882-888

80. Belzile JP, Duisit G, Rougeau N, Mercier J, Finzi A, Cohen EA: HIV-1 Vprmediated $\mathrm{G} 2$ arrest involves the DDB1-CUL4AVPRBP E3 ubiquitin ligase. PLoS Pathog 2007, 3:e85. 
81. DeHart JL, Zimmerman ES, Ardon O, Monteiro-Filho CM, Arganaraz ER Planelles V: HIV-1 Vpr activates the G2 checkpoint through manipulation of the ubiquitin proteasome system. Virol J 2007, 4:57

82. Hrecka K, Gierszewska M, Srivastava S, Kozaczkiewicz L, Swanson SK Florens L, Washburn MP, Skowronski J: Lentiviral Vpr usurps Cul4DDB1 [VprBP] E3 ubiquitin ligase to modulate cell cycle. Proc Nat/ Acad SciUSA 2007, 104:11778-11783.

83. Le Rouzic E, Belaidouni N, Estrabaud E, Morel M, Rain JC, Transy C, Margottin-Goguet F: HIV1 Vpr arrests the cell cycle by recruiting DCAF1/NprBP, a receptor of the Cul4-DDB1 ubiquitin ligase. Cell Cycle 2007, 6:182-188

84. Schrofelbauer B, Hakata Y, Landau NR: HIV-1 Vpr function is mediated by interaction with the damage-specific DNA-binding protein DDB1. Proc Natl Acad Sci USA 2007, 104:4130-4135.

85. Tan L, Ehrlich E, Yu XF: DDB1 and Cul4A are required for human immunodeficiency virus type 1 Vpr-induced G2 arrest. J Virol 2007, 81:10822-10830.

86. Wen X, Duus KM, Friedrich TD, de Noronha CM: The HIV1 protein Vpr acts to promote $\mathrm{G} 2$ cell cycle arrest by engaging a DDB1 and Cullin4Acontaining ubiquitin ligase complex using VprBP/DCAF1 as an adaptor. J Biol Chem 2007, 282:27046-27057.

87. Zhao LJ, Mukherjee S, Narayan O: Biochemical mechanism of HIV-I Vpr function. Specific interaction with a cellular protein. J Biol Chem 1994, 269:15577-15582

88. Angers S, Li T, Yi X, MacCoss MJ, Moon RT, Zheng N: Molecular architecture and assembly of the DDB1-CUL4A ubiquitin ligase machinery. Nature 2006, 443:590-593.

89. He YJ, McCall CM, Hu J, Zeng Y, Xiong Y: DDB1 functions as a linker to recruit receptor WD40 proteins to CUL4-ROC1 ubiquitin ligases. Genes Dev 2006, 20:2949-2954.

90. Higa LA, Zhang H: Stealing the spotlight: CUL4-DDB1 ubiquitin ligase docks WD40-repeat proteins to destroy. Cell Div 2007, 2:5.

91. Jin J, Arias EE, Chen J, Harper JW, Walter JC: A family of diverse Cul4Ddb1-interacting proteins includes $\mathrm{Cdt} 2$, which is required for $\mathrm{S}$ phase destruction of the replication factor Cdt1. Mol Cell 2006, 23:709-721.

92. Schrofelbauer B, Yu Q, Zeitlin SG, Landau NR: Human immunodeficiency virus type 1 Vpr induces the degradation of the UNG and SMUG uracilDNA glycosylases. J Virol 2005, 79:10978-10987.

93. Le Rouzic E, Morel M, Ayinde D, Belaidouni N, Letienne J, Transy C, Margottin-Goguet F: Assembly with the Cul4A-DDB1DCAF1 ubiquitin ligase protects HIV-1 Vpr from proteasomal degradation. I Biol Chem 2008, 283:21686-21692.

94. Binette J, Dube M, Mercier J, Halawani D, Latterich M, Cohen EA: Requirements for the selective degradation of $\mathrm{CD} 4$ receptor molecules by the human immunodeficiency virus type 1 Vpu protein in the endoplasmic reticulum. Retrovirology 2007, 4:75.

95. Margottin F, Bour SP, Durand H, Selig L, Benichou S, Richard V, Thomas D, Strebel K, Benarous R: A novel human WD protein, h-beta $\operatorname{TrCp}$, that interacts with HIV-1 Vpu connects CD4 to the ER degradation pathway through an F-box motif. Mol Cell 1998, 1:565-574.

96. Douglas JL, Viswanathan K, McCarroll MN, Gustin JK, Fruh K, Moses AV: Vpu directs the degradation of the human immunodeficiency virus restriction factor BST-2/Tetherin via a \{beta\}TrCP-dependent mechanism. J Virol 2009, 83:7931-7947.

97. Mangeat B, Gers-Huber G, Lehmann M, Zufferey M, Luban J, Piguet V: HIV1 Vpu neutralizes the antiviral factor Tetherin/BST-2 by binding it and directing its beta-TrCP2-dependent degradation. PLoS Pathog 2009, 5:e1000574.

98. Yu X, YU Y, Liu B, Luo K, Kong W, Mao P, Yu XF: Induction of APOBEC3G ubiquitination and degradation by an HIV-1 Vif-Cul5-SCF complex. Science 2003, 302:1056-1060.

99. Mehle A, Strack B, Ancuta P, Zhang C, McPike M, Gabuzda D: Vif overcomes the innate antiviral activity of APOBEC3G by promoting its degradation in the ubiquitin-proteasome pathway. J Biol Chem 2004, 279:7792-7798.

100. Wiegand HL, Doehle BP, Bogerd HP, Cullen BR: A second human antiretroviral factor, APOBEC3F, is suppressed by the HIV-1 and HIV-2 Vif proteins. EMBO J 2004, 23:2451-2458.

101. Yu Y, Xiao Z, Ehrlich ES, Yu X, YU XF: Selective assembly of HIV-1 Vif-Cul5ElonginB-ElonginC E3 ubiquitin ligase complex through a novel SOCS box and upstream cysteines. Genes Dev 2004, 18:2867-2872.
102. Brasey A, Lopez-Lastra M, OhImann T, Beerens N, Berkhout B, Darlix JL, Sonenberg $\mathrm{N}$ : The leader of human immunodeficiency virus type 1 genomic RNA harbors an internal ribosome entry segment that is active during the G2/M phase of the cell cycle. J Virol 2003, 77:3939-3949.

103. Goh WC, Rogel ME, Kinsey CM, Michael SF, Fultz PN, Nowak MA, Hahn BH, Emerman M: HIV-1 Vpr increases viral expression by manipulation of the cell cycle: a mechanism for selection of Vpr in vivo. Nat Med 1998, 4:65-71.

104. Kewalramani VN, Park CS, Gallombardo PA, Emerman M: Protein stability influences human immunodeficiency virus type $2 \mathrm{Vpr}$ virion incorporation and cell cycle effect. Virology 1996, 218:326-334.

105. Planelles V, Jowett JB, Li QX, Xie Y, Hahn B, Chen IS: Vpr-induced cell cycle arrest is conserved among primate lentiviruses. J Virol 1996 70:2516-2524

106. Stivahtis GL, Soares MA, Vodicka MA, Hahn BH, Emerman M:Conservation and host specificity of Vpr-mediated cell cycle arrest suggest a fundamental role in primate lentivirus evolution and biology. J Virol 1997, 71:4331-4338.

107. Matsuda M, Arai A, Nakamura Y, Fujisawa R, Masuda M: Host cell-specific effects of lentiviral accessory proteins on the eukaryotic cell cycle progression. Microbes Infect 2009, 11:646-653.

108. Belshan M, Mahnke LA, Ratner L: Conserved amino acids of the human immunodeficiency virus type $2 \mathrm{Vpx}$ nuclear localization signal are critical for nuclear targeting of the viral preintegration complex in nondividing cells. Virology 2006, 346:118-126.

109. Cheng X, Belshan M, Ratner L: Hsp40 facilitates nuclear import of the human immunodeficiency virus type $2 \mathrm{Vpx}$-mediated preintegration complex. J Virol 2008, 82:1229-1237.

110. Belshan M, Ratner L: Identification of the nuclear localization signal of human immunodeficiency virus type 2 Vpx. Virology 2003, 311:7-15.

111. Depienne C, Roques P, Creminon C, Fritsch L, Casseron R, Dormont D, Dargemont C, Benichou S: Cellular distribution and karyophilic properties of matrix, integrase, and Vpr proteins from the human and simian immunodeficiency viruses. Exp Cell Res 2000, 260:387-395.

112. Mahalingam S, Van Tine B, Santiago ML, Gao F, Shaw GM, Hahn BH: Functional analysis of the simian immunodeficiency virus Vpx protein: identification of packaging determinants and a novel nuclear targeting domain. J Virol 2001, 75:362-374.

113. Pancio HA, Heyden N Vander, Ratner L: The C-terminal proline-rich tail of human immunodeficiency virus type $2 \mathrm{Vpx}$ is necessary for nuclear localization of the viral preintegration complex in nondividing cells. $J$ Virol 2000, 74:6162-6167.

114. Akari H, Sakuragi J, Takebe Y, Tomonaga K, Kawamura M, Fukasawa M, Miura T, Shinjo T, Hayami M: Biological characterization of human immunodeficiency virus type 1 and type 2 mutants in human peripheral blood mononuclear cells. Arch Virol 1992, 123:157-167.

115. Gibbs JS, Regier DA, Desrosiers RC: Construction and in vitro properties of SIVmac mutants with deletions in "nonessential" genes. AIDS Res Hum Retroviruses 1994, 10:607-616.

116. Guyader M, Emerman M, Montagnier L, Peden K: VPX mutants of HIV-2 are infectious in established cell lines but display a severe defect in peripheral blood lymphocytes. Embo J 1989, 8:1169-1175.

117. Kappes JC, Conway JA, Lee SW, Shaw GM, Hahn BH: Human immunodeficiency virus type 2 vpx protein augments viral infectivity. Virology 1991, 184:197-209.

118. Kawamura M, Sakai H, Adachi A: Human immunodeficiency virus Vpx is required for the early phase of replication in peripheral blood mononuclear cells. Microbiol Immunol 1994, 38:871-878.

119. Kappes JC, Parkin JS, Conway JA, Kim J, Brouillette CG, Shaw GM, Hahn BH: Intracellular transport and virion incorporation of vpx requires interaction with other virus type-specific components. Virology 1993, 193:222-233.

120. Yu XF, Yu QC, Essex M, Lee TH: The vpx gene of simian immunodeficiency virus facilitates efficient viral replication in fresh lymphocytes and macrophage. J Virol 1991, 65:5088-5091.

121. Goujon C, Arfi V, Pertel T, Luban J, Lienard J, Rigal D, Darlix JL, Cimarelli A: Characterization of simian immunodeficiency virus SIVSM/human immunodeficiency virus type $2 \mathrm{Vpx}$ function in human myeloid cells. $J$ Virol 2008, 82:12335-12345.

122. Goujon C, Riviere L, Jarrosson-Wuilleme L, Bernaud J, Rigal D, Darlix JL, Cimarelli A: SIVSM/HIV-2 Vpx proteins promote retroviral escape from a 

dendritic cells. Retrovirology 2007, 4:2.

123. Mangeot PE, Duperrier K, Negre D, Boson B, Rigal D, Cosset FL, Darlix JL: High levels of transduction of human dendritic cells with optimized SIV vectors. Mol Ther 2002, 5:283-290.

124. Wolfrum N, Muhlebach MD, Schule S, Kaiser JK, Kloke BP, Cichutek K, Schweizer M: Impact of viral accessory proteins of SIVsmmPBj on early steps of infection of quiescent cells. Virology 2007, 364:330-341

125. Gibbs JS, Lackner AA, Lang SM, Simon MA, Sehgal PK, Daniel MD, Desrosiers RC: Progression to AIDS in the absence of a gene for vpr or vpx. J Virol 1995, 69:2378-2383.

126. Hirsch VM, Sharkey ME, Brown CR, Brichacek B, Goldstein S, Wakefield J, Byrum R, Elkins WR, Hahn BH, Lifson JD, Stevenson M: Vpx is required for dissemination and pathogenesis of SIV(SM) PBj: evidence of macrophage-dependent viral amplification. Nat Med 1998 4:1401-1408.

127. Fujita M, Otsuka M, Miyoshi M, Khamsri B, Nomaguchi M, Adachi A: Vpx is critical for reverse transcription of the human immunodeficiency virus type 2 genome in macrophages. J Virol 2008, 82:7752-7756.

128. Kaushik R, Zhu X, Stranska R, Wu Y, Stevenson M: A cellular restriction dictates the permissivity of nondividing monocytes/macrophages to lentivirus and gammaretrovirus infection. Cell Host Microbe 2009, 6:68-80.

129. Srivastava S, Swanson SK, Manel N, Florens L, Washburn MP, Skowronski J: Lentiviral Vpx accessory factor targets VprBP/DCAF1 substrate adaptor for cullin 4 E3 ubiquitin ligase to enable macrophage infection. PLOS Pathog 2008, 4:e1000059.

130. Sharova N, Wu Y, Zhu X, Stranska R, Kaushik R, Sharkey M, Stevenson M: Primate lentiviral Vpx commandeers DDB1 to counteract a macrophage restriction. PLoS Pathog 2008, 4:e1000057.

131. Madani N, Kabat D: An endogenous inhibitor of human immunodeficiency virus in human lymphocytes is overcome by the viral Vif protein. J Virol 1998, 72:10251-10255.

132. Simon JH, Gaddis NC, Fouchier RA, Malim MH: Evidence for a newly discovered cellular anti-HIV-1 phenotype. Nat Med 1998, 4:1397-1400.

133. Keckesova Z, Ylinen LM, Towers GJ: The human and African green monkey TRIM5alpha genes encode Ref1 and Lv1 retroviral restriction factor activities. Proc Natl Acad Sci USA 2004, 101:10780-10785.

134. Nisole S, Lynch C, Stoye JP, Yap MW: A Trim5-cyclophilin A fusion protein found in owl monkey kidney cells can restrict HIV-1. Proc Natl Acad SCi USA 2004, 101:13324-13328.

135. Sayah DM, Sokolskaja E, Berthoux L, Luban J: Cyclophilin A retrotransposition into TRIM5 explains owl monkey resistance to HIV-1. Nature 2004, 430:569-573.

136. Stremlau M, Owens CM, Perron MJ, Kiessling M, Autissier P, Sodroski J: The cytoplasmic body component TRIM5alpha restricts HIV-1 infection in Old World monkeys. Nature 2004, 427:848-853.

137. Yap MW, Nisole S, Lynch C, Stoye JP: Trim5alpha protein restricts both HIV-1 and murine leukemia virus. Proc Natl Acad Sci USA 2004, 101:10786-10791

138. Schule S, Kloke BP, Kaiser JK, Heidmeier S, Panitz S, Wolfrum N, Cichutek K, Schweizer M: Restriction of HIV-1 replication in monocytes is abolished by Vpx of SIVsmmPBj. PLoS One 2009, 4:e7098.

139. Berger G, Goujon C, Darlix JL, Cimarelli A: SIVMAC Vpx improves the transduction of dendritic cells with nonintegrative HIV-1-derived vectors. Gene Ther 2009, 16:159-163.

140. Goujon C, Jarrosson-Wuilleme L, Bernaud J, Rigal D, Darlix JL, Cimarelli A: With a little help from a friend: increasing HIV transduction of monocyte-derived dendritic cells with virion-like particles of SIV(MAC). Gene Ther 2006, 13:991-994.

doi: $10.1186 / 1742-4690-7-35$

Cite this article as: Ayinde et al., Limelight on two HIV/SIV accessory pro-

teins in macrophage infection: Is Vpx overshadowing Vpr? Retrovirology 2010, 7:35

\section{Submit your next manuscript to BioMed Central} and take full advantage of:

- Convenient online submission

- Thorough peer review

- No space constraints or color figure charges

- Immediate publication on acceptance

- Inclusion in PubMed, CAS, Scopus and Google Scholar

- Research which is freely available for redistribution

Submit your manuscript at www.biomedcentral.com/submit
C Biomed Central 